\title{
Application of a Geomatics Approach for the Diachronic Study of the Meditterannean Coastline Case of Tangier Bay
}

\author{
Fatima Zahra Salim*, Mohammed Yassine El Habti, Lech-Hab Khadija Ben Hamman, \\ Ahmed Raissouni, Abdelkrim El Arrim
}

Laboratoire «Environnement, Océanologie, et Ressources Naturelles», Dpt. des Sciences dela Terre, FST de Tanger, Km 9, Route de Ziatine, Maroc

Email:*s-fati@hotmail.com

How to cite this paper: Salim, F.Z., El Habti, M.Y., Hamman, L.-H.K.B., Raissouni, A. and El Arrim, A. (2018) Application of a Geomatics Approach for the Diachronic Study of the Meditterannean Coastline Case of Tangier Bay. International Journal of Geosciences, 9, 320-336. https://doi.org/10.4236/ijg.2018.96020

Received: February 24, 2018

Accepted: June 23, 2018

Published: June 26, 2018

Copyright $\odot 2018$ by authors and Scientific Research Publishing Inc. This work is licensed under the Creative Commons Attribution International License (CC BY 4.0).

http://creativecommons.org/licenses/by/4.0/

\begin{abstract}
The coastline is one of the country's most important environmental and economic resources. However, it is a delicate and highly coveted environment on which many factors of evolution interact, both anthropogenic and natural. This work is concerned with the diachronic study of the coastline of the Mediterranean coast, particularly the coastal fringe at the level of Tangier Bay. In order to experimentally confirm the numerical models used and to take part in the development of an accurate, reliable and rapid decision support system for the assessment and remediation of the risks of accretion and coastal erosion, the methodology followed consists of the application of automatic analytical techniques, based on a geomatics approach, using a multi-temporal photo-interpretation, a Geographical Information System (GIS) and a computerized data analysis system (DSAS: Digital Shoreline Analysis System). The change rate will be calculated from the multi-date maps (1981-96 and 2017) using the End Point Rate (EPR). To achieve our objective, the study area was divided into three sectors from East to West: El Ghandouri Beach, Malabata Beach and the municipal square adjacent to the port. The GIS analysis of the data obtained shows that the coastline is present by location and for the three periods of comparison of the remarkable zones of erosion and sedimentation.
\end{abstract}

\section{Keywords}

Mediterranean Coastline, (SIG) Geographic Information System, (DSAS)

Digital Shoreline Analysis System, Accretion, Erosion 


\section{Introduction}

The coastal fringe is the meeting point of the Earth and the Sea and defining it is not simple. One could say that this is the level playing field between terrestrial and marine ecosystems. The fauna and flora found there are certainly very diverse but especially fragile. Its concrete delineation remains in practice very vague. It is a vulnerable space, in constant evolution.

Morocco's coastline, with its two coastlines, Mediterranean and Atlantic, extends over approximately $3500 \mathrm{~km}$. This belt, with its urban agglomerations and various activities, contributes to the structuring of the national economy. This highly coveted space is subject to multiple forms of pressure, which can be considered as the source of environmental risks. Indeed, it is the place of a rapid urbanization organized and disorganized, but also of implantation of industrial projects, port, tourist and fishing activities. In short, the Moroccan coastline is the place where all the pressures of economic and demographic development accumulate and where competition for land appropriation is particularly severe [1]. The degradation of coastlines is therefore a global reality on which two main factors influence: Eustatic movements and the reduction, sometimes even disappearance, of sedimentary inputs to the coast. Morocco's coastlines are no exception to this erosion. In the context of the sustainable development of the country, it is necessary to take this into account when planning coastal tourism.

The purpose of this article is meant to understand the role played by anthropogenic developments, in particular the work of the new marina, as well as natural factors in the historical evolution of the coastline of Tangier Bay, and to identify areas in erosion and accretion. The diachronic study is based on photo-interpretation (air photos, satellite images) and the construction of a geographic information system (GIS) combined with a digital Shoreline analysis system (DSAS Digital shoreline Analysis System) and field observations and surveys.

\section{Study Area}

Tangier Bay is a coastal sedimentological entity of great hydrodynamic and sedimentary importance, due to its particular geographical position on both sides of the Strait of Gibraltar, a place of exchange between the Atlantic and the Mediterranean [2]. It is located at the north-western end of Morocco, on the southern bank of the Strait of Gibraltar, between $35^{\circ} 46^{\prime}$ and $35^{\circ} 48^{\prime} \mathrm{N}$ and $5^{\circ} 45^{\prime}$ and $5^{\circ} 49^{\prime} \mathrm{W}$. It forms the maritime part of a depression dug between two rocky peaks that open into the Strait of Gibraltar: Cape Spartel to the West and Cape Malabata to the East (Figure 1).

Three large geomorphological units can be distinguished [3]: The sandstone massif of Jbel El Kebir in the West $(200 \mathrm{~m})$, the hilly plain of the Fahs in the centre $(100 \mathrm{~m})$ and the Anjera massifs in the East.

In geological terms, Tangier Bay represents the northern extension of the External Domain of the aquifer zone of the Rifain system. The geology of the 


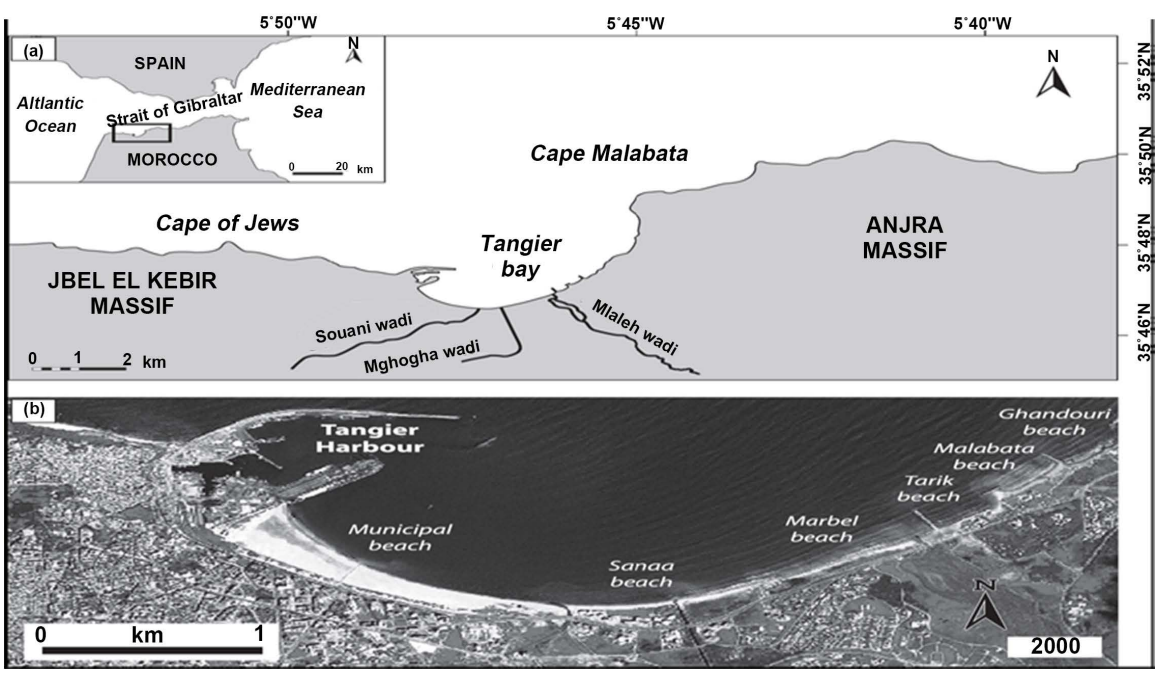

Figure 1. Location of Tangier Bay, Morocco (El Arrim, A. et al., 2001).

hinterland is characterized by the stacking of four layers of flyschs which rest on the Tangier unit: Melloussa, Béni-Ider, Tisirène and the numidian layer [4].

On the hydrology side, the Tangier zone is characterized by an average annual rainfall of $800 \mathrm{~mm}$. The bay is home to a fairly dense hydrographic network, consisting of four main temporary wadis from West to East: wadi Souani, wadi Mghogha, wadi Mlaleh and wadi Chatt. The annual solid flow of all wadis entering the bay is estimated at between 60,000 and 70,000 t/year, including 5000 to $10,000 \mathrm{~m}^{3}$ of sand, gravel and pebbles [5].

From the hydrodynamic point of view, swells come mainly from two sectors:

- The swells in the area, westward to NW, come from the Atlantic and dominate off the bay. The periods are of the order of 9 and $12 \mathrm{~s}$ with an amplitude of $2 \mathrm{~m}$;

- The swells in the second sector, east-to-east to NE direction, are due to local wind seas, characterized by short periods of 3 to $5 \mathrm{~s}$, and heights of less than $1.5 \mathrm{~m}$. These swells alter the coastline to the east of the bay with an incidence of $20^{\circ}$ to $30^{\circ}$, resulting in a lateral transfer from East to West.

The tide is of the semi-diurnal type with an average amplitude of $1.8 \mathrm{~m}$. The tidal range of the white water is $2.2 \mathrm{~m}$ and the tidal range of the overburden is $0.8 \mathrm{~m} \mathrm{[6]}$.

The size of sediment grains depends on several factors including: the mineralogical composition of detritic particles and their erosion and transport history. The combination of these factors results in particle deposition of varying particle types and particle size distributions [7].

The surface sediments of Tangier Bay, generally silico-clastic in nature, consist of sand of varying sizes. Carbonates are almost exclusively calcitic. Their generally variable contents show an increasing evolution of the shoreline (11\%) towards the bay $(23 \%)$ where carbonate-tested organogenic debris contributes to this increase [8]. Granulometric analysis of surface sediments shows the presence of three main facies: 
A sandy facies, characterized by sand content above $70 \%$. This facies occupies a strip parallel to the coast, $1.5 \mathrm{~km}$ long towards the $\mathrm{SW}$, which can extend up to $15 \mathrm{~m}$ deep;

A silty facies, with sand content of less than $35 \%$. It is located opposite the mouths of the Souani and Mghogha wadis, and thus constitutes the internal mudflat in relation to the contributions of these wadis, a favorable place for the decantation of materials from continental outfalls;

A mixed facies consists of a mixture of sand and silt with a sand content of between $30 \%$ and $70 \%$. This type of facies characterizes the western part of the bay, which is generally sheltered from the NW swell and appears as muddy sand and sandy silt.

The distribution of sand along the coast of Tangier Bay highlights two sections of beach: The first, extending from the wadi Mghogha to the harbour, consists of moderately classified fine sands. The second, which goes from the wadi Mghogha to the tip of Malabata, consists of medium sands, well to very well ranked [9].

From a recent sedimentary dynamic point of view, Tangier Bay is characterized by the variety of sedimentary environments, distinct from each other by their hydrodynamic and environmental characteristics, as well as by the nature of sedimentary processes and deposits [10].

In Tangier Bay as a whole, the distribution of sediments on both the coastline and seabed is generally controlled by hydrodynamic factors, as well as by the main sources of input (wadis). The sandy sediments appear in the eastern zone, where the NNE and NE swell predominates, reflecting a turbulent environment. In the western zone, which is generally more protected from the action of NW swells, fine sediments are becoming increasingly important, along with other mixtures of facies such as silty sand and sandy mud. The distribution of minerals reveals a detritic continental origin from the hinterland formations. The surface sediments present in Tangier Bay could have two possible origins [8]: the solid inputs of the main watercourses overlooking Tangier Bay, in particular the Souani, Mlaleh and Mghogha wadis; and the erosion of the clay-grite-clay cliffs overlooking the Tangier Bay shoreline, which excavate most of the coarse fraction.

\section{Material and Methods}

In this research, we have used a methodological approach that uses the classical techniques of digital geographic information processing, highly appreciated in coastal kinematics and described by many authors [11].

In order to extract the reference lines from the documents selected to observe and analyse the spatio-temporal evolution of the sandy coastline of the Tangier Bay region on a regional and local scale, we have adopted the following methodological approach: First, the selection of a reference line adapted to the field of study and the type of documents used; then the geometrical rectification of the available data, ex- 
traction of the selected reference lines, then photo-interpretation and finally the determination of the rate of change of the coastline.

\subsection{Basic Data}

The kinematics of the coastline are studied by photo-interpretation using two vertical aerial photographs acquired in panchromatic mode (dated 1981 and 1996) and a satellite image (2017) (Figure 2-4). The scales are $1 / 40,000$, covering a period of 37 years (Table 1), the Google Earth 2017 image is characterized by a high resolution of $10 \mathrm{~m}$. Thus, several dates are often recommended in order to obtain a better result of the temporal evolution of the coastline, the precision of the evolution rate calculation increases with the number of coastlines used [12]. A topographic map of Tangier (1965) with a scale of 1:50,000 was also used for the geometric correction of aerial photographs.

\subsection{Software and Tools Used}

Three tools were used in this study:

- The ArcGis 10.5 is a GIS processing and mapping software with its multiple extensions, it allows the final processing of data and the production of thematic maps;

- DSAS 4.3.4, which is a tool developed by United State Geological Survey. The "Digital Shoreline Analysis System" is a GIS application for ArcGIS 10.5, allowing the calculation of trend rate statistics on transects perpendicular to the coastline;

- Google Earth Pro, which is a tool designed for professionals to increase productivity, communicate visually and share geographic information. Indeed, this version allows the import of GIS (Geographic Information Systems) data, high resolution printing (up to 4800 pixels) and area measurement.

\subsection{Methodology Used to Study the Kinematics of the Coastline}

\subsubsection{Select Reference Line}

Indicators are used to indicate reference lines according to media and detection methods. In a diachronic study based on photo-interpretation, the choice and extraction of a line in conjunction with the different images used is necessary [13]. The inventory and description of the main indicators of the coastline lines

Table 1. Characteristics of aerial photos and satellite images used.

\begin{tabular}{ccccc}
\hline Date & Document type & Scale & Image type & Number of aerial photos or satellite images used \\
\hline 1981 & Aerial photo & $1 / 40,000$ & Black \& White & 2 \\
1996 & Aerial photo & $1 / 40,000$ & Black \& White & 2 \\
2017 & Google Earth & $1 / 40,000$ & Color & 1 \\
\hline
\end{tabular}




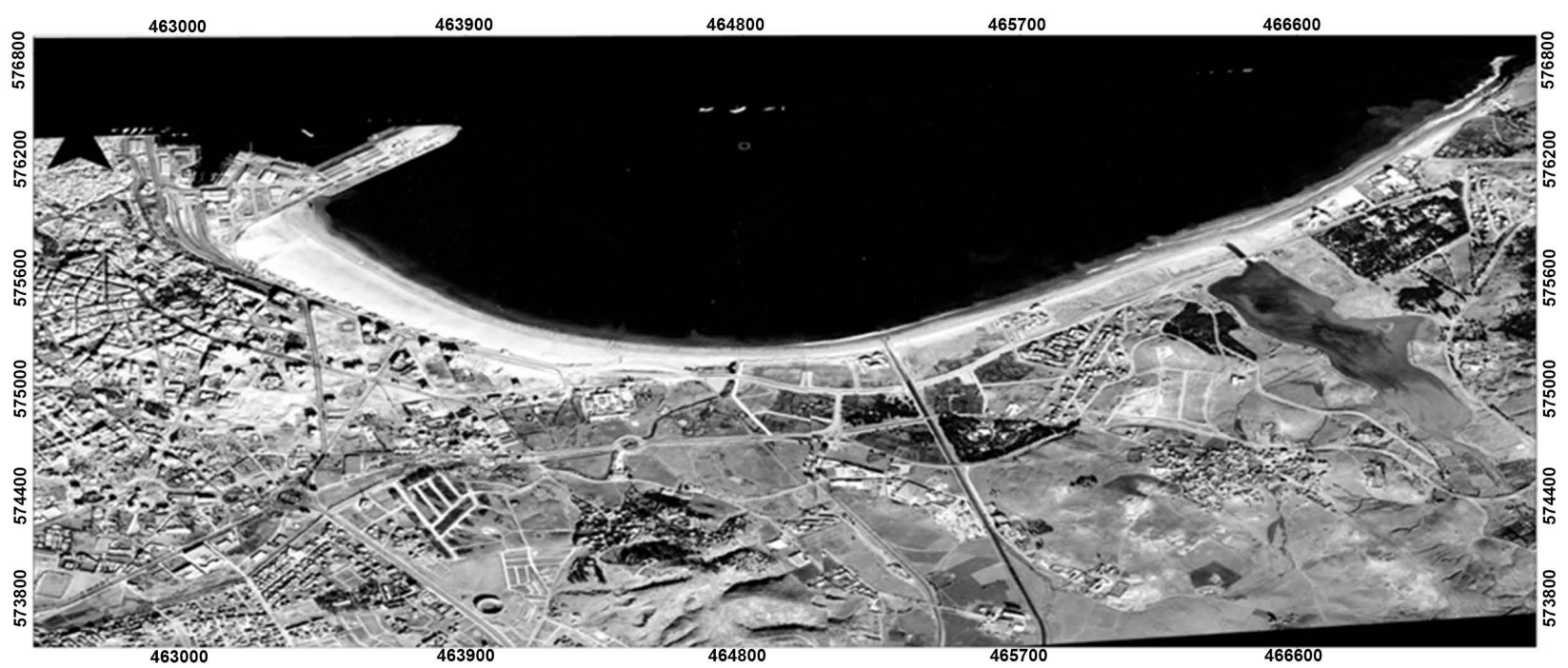

Figure 2. Aerial photo of Tangier Bay in 1981.

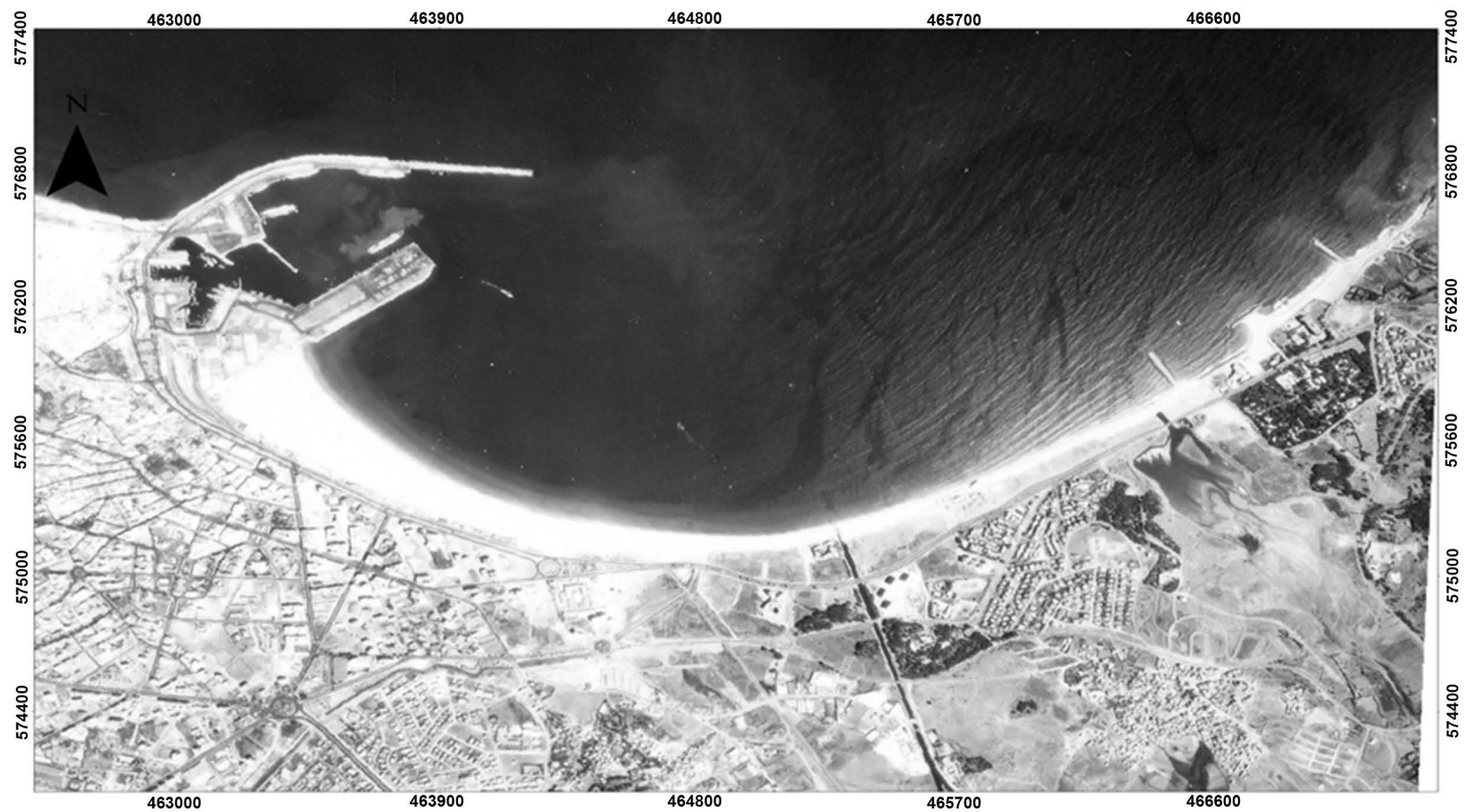

Figure 3. Aerial photo of Tangier Bay in 1996.

recorded in the photographs and the image from 1981 to 2017 make it possible to identify by elimination the reference line selected for the diachronic study.

\subsubsection{Detecting Indicators of Coastline Identification}

To this end, we have chosen the most suitable indicators for reconstituting the kinematics of the sandy coasts of Tangier Bay. The field observations made during our field trips to the study site and the quality of aerial photographs enabled us to define the most relevant reference line in the Tangier Bay coast: the High Water Line (High Tide Line). This is the indicator most commonly 


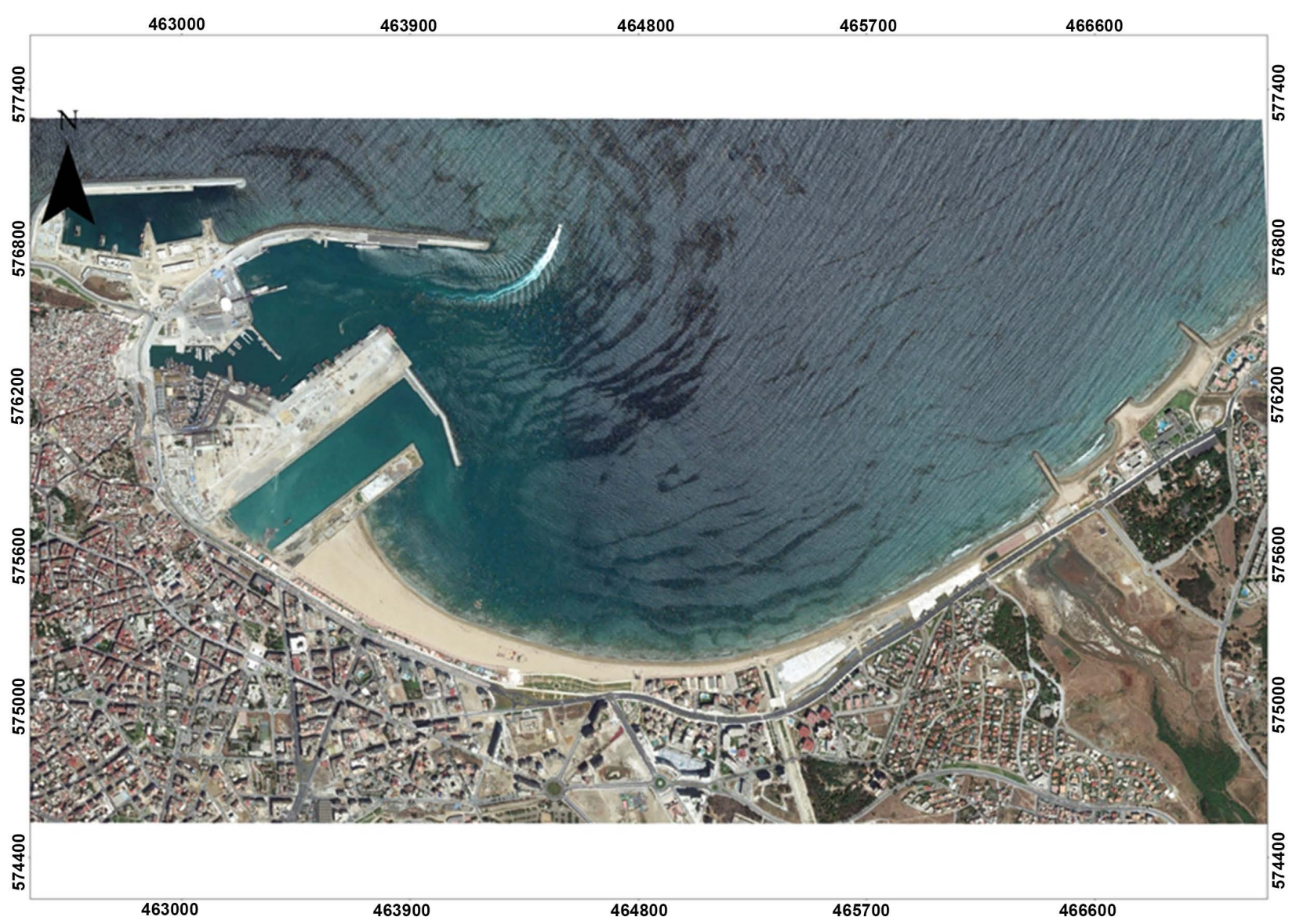

Figure. 4. Satellite image of tangier bay 2017.

used by Anglo-Saxons to study shoreline variations [14] [15] [16]. It was defined as the level reached by the last high tide [17].

\subsubsection{Developing and Processing Input Data \\ 1) Geo-referencing}

Thanks to the ArcGis software, geo-referencing was carried out in order to produce Raster type data with a well-defined projection system, this facilitates the integration of these same data into the ArcGis software for later operations.

For the geo-referencing of topographic maps, we firstly located the location of the different crosspieces used for calibration, then we introduced the real coordinates in meters of the control point. The same operation was repeated for at least 4 other calibration points in order to obtain a reliable accuracy. To conclude, and before recording the geo-referenced map, we defined Lambert's conformal conical projection system (Nord Maroc Lambert I) as the projection system to which our zone belongs.

With regard to the geo-referencing of aerial photos and satellite images, the geo-referenced topographic map was used in advance, so identical points on both (round points, national roads ... are identified and used as reference points for calibration). The image is therefore superimposed on the geo-referenced map 
and ready to be processed in the following steps.

\section{2) Geometric correction}

This is the spatial arrangement of objects, their geometrical relationships without substantial modification of the data content. Aerial shots being of different scales and affected by numerous deformations making their geometry imperfect [14] [17] [18] [19] [20] [21]. It is necessary to look for a deformation model to correct these defects and bring the images into conformity. This operation allows precise measurements and conditions the quality of the results, which is why we will first insist on it before setting out the procedure for interpreting and digitizing the reference lines.

\section{- Mosaic painting of aerial photos}

When images that have just been georeferenced are displayed in an unstable state, it is essential to perform a mosaic step (grouping of images and improvement of the whole). The mosaic operation therefore consists of removing the edges of the plates, reducing and treating the overlapping areas and homogenizing the colors and their dynamics throughout the study area according to the following steps:

- Roughly distorting the edges of photos (manual work);

- Manual elimination, on the overlapping or overlapping areas, of the parts of plates that are the least well set or the least contrasted;

- Fine manual precision of the cliché limits based on physical limits (roads or paths, parcel boundaries ...);

- Pixel values averaging at the edge of shots (automatic working);

- Homogenization of color dynamics on the whole mosaic (automatic working);

- Demarcation of the study area.

\section{- Photo-interpretation and digitization of reference lines}

With the ArcViewGis software (ArcGis 10.5) we performed visual interpretation and scanning of reference lines on aerial images. The approach of photo-interpretation revolves around three phases [13] [22]: Object recognition, which depends on the perception and visual knowledge of the object sought; analysis and interpretation, which lead to the identification of the objects observed by inductive-deductive reasoning and verification; and finally, the synthesis of information by modeling the contours of the object(s) sought.

Based on these principles, the first step was to study the images in order to recognize what is being observed (vegetation, dunes, beach, coastal development, etc.) and then digitization of the reference line directly on the screen against a backdrop of rectified images. Depending on the contrasts, we choose the pixels attributable to the reference line by convention. The occupation of the seafront (road network, habitat, tourist facilities, dunes, culture, industrial unit, etc.) has also been digitized and constitutes a second layer of vectorial information. After the input operation, an attribute is assigned to each scanned item. Thus, a land use file and a coastal linear file are obtained, each linked to an attribute table on 
which are indicated, for all segments of the mapped coastline, the nature of the digitized entity (upper wetland boundary, vegetation boundary, house boundary, riprap, dune foot), its length and the degree of reliability of digitization (certain, uncertain).

\section{- Uncertainties, estimation of errors affecting reference lines}

Regardless of the technique and methodological approach used to measure the evolution of a coastline from iconographic documents, the evolution rates obtained always involve a certain fraction of uncertainty, which must be evaluated in order to assess the degree of representativeness of the results and exploit them appropriately [20]. The objective is to analyze all sources of uncertainty related to the quality of the mobilized data, short-term variations in the position of the solid sea line and the treatments applied to extract reference lines from aerial images. References [13] [14] [17] [19] [21] suggest that the superimposition of observed terrestrial characteristics on aerial photographs and a map at this scale can lead to an error of \pm 10 metres in relation to reality. The coastline also is not always well visible on some aerial photographs, the lines drawn by the tide can then appear slightly blurred, so we have an uncertainty to pinpoint the coastline with precision. The higher the number of calibration points, the smaller the uncertainty. The RMS errors (Table 2) for each image were greater than or equal to $0.22 \mathrm{~m}$. However, this error must be reduced to $\pm 1 \mathrm{~m} \mathrm{[23]} \mathrm{(Table} \mathrm{3).}$

\subsection{Measuring and Statistical Calculation Tool for the Evolution of the Coastline}

The choice of a technique depends on several factors [14]. Generally, this choice must take into account the data used, the selected coastline and the precision required through such a study [14] [15].

In our study, we measured linear evolutions automatically using the Geographic Information System (GIS) using the Digital Shoreline Analysis System (DSAS version 4.2), which is a module of ArcGIS 10.5 (ESRI, Redlands, California) developed by the US Geological Survey [24], following transects perpendicular to the lines to be compared (Figure 5). These land/sea transects, spaced 50 $\mathrm{m}$ apart, are generated from a baseline. The DSAS measures the distances between the intersection points of transects and coastlines, calculates the rates of change along each transect, and describes the results in the form of attribute tables. Then, all generated transects are checked to verify and eliminate aberrations or those located in areas where reference lines could not be scanned

Table 2. RMS errors related to image correction.

\begin{tabular}{|c|c|c|}
\hline Dates of shooting & Number of calibration points & RMS error (m) \\
\hline 1981 & 8 & 0.40 \\
\hline 1996 & 10 & 0.70 \\
\hline 2017 & 4 & 0.50 \\
\hline \multicolumn{2}{|c|}{ Average } & 0.53 \\
\hline
\end{tabular}


Table 3. Estimated overall margin of error.

\begin{tabular}{cc}
\hline Error category & Estimated value \\
\hline Errors in the determination of reference points & \pm 10 \\
Measurement errors in corrected aerial photographs & \pm 1 \\
Overall error & 0.29 \\
\hline
\end{tabular}
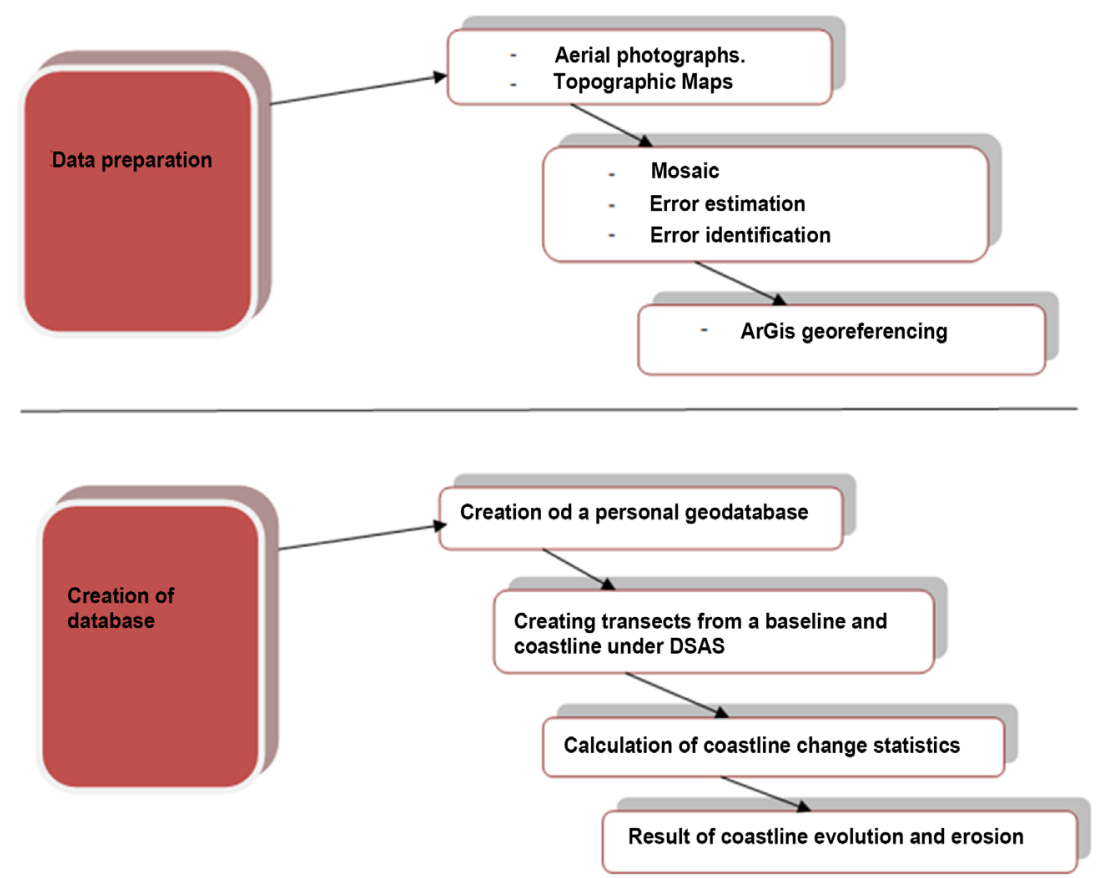

Figure 5. Diagram illustrating the necessary steps for statistical calculations of the rate of change using the DSAS application under ARCGIS 10.5.

and in areas where the quality of georeferencing was poor. Finally, the analysis of the automatically generated attribute tables makes it possible to estimate the coastal kinematics and to map the evolution rates. Among the indices proposed by DSAS, we have chosen the EPR index (End Point Rate) in order to understand the temporal evolution of the coastline position, it will allow us to devalue the evolution between the location of two successive coastlines and to estimate the evolution rates of each site over the entire study period.

\section{EPR (End Point Rate):}

The EPR or extreme point method is the ratio of the distance between the oldest and most recent coastline line over time (number of years elapsed between the two dates). This attribute, expressed in metres/year, is presented in the cartographic model under the heading "annual average". The EPR is suitable when two coastlines are available to evaluate shoreline kinematics [25]. Orthogonal transects are generated, automatically, at a specified spacing, all along the coastline using DSAS when the "Personal Geodatabase" is ready in ArcGIS. They are equidistant and perpendicular to the baseline and represent fairly finely the evolution of the coastline. Finally, after creating the orthogonal transects, DSAS 
calculates the mean, minimum and maximum coastline modification velocity along each calculating transect. The evolution rate for each period is also calculated using EPR methods.

As part of this work, transects are generated every 50 meters in order to accurately represent the evolution of the coastline and highlight the different aberrations (Erosive transect in an accretion zone or vice versa). We then carry out statistical calculations of the evolution of the coastline on all transects, then a cartography work under the ArcGIS 10.5 will allow us to interpret the results.

\section{Results}

The outcome of our study represents a synthesis of the coastal changes that have taken place since the 20th century on the coastline of Tangier Bay, stretching over a cumulative coastline of almost $5 \mathrm{~km}$. In a first step, the successive positions of each selected reference line are compared in order to understand the temporal variations of the coastal kinematics. In some sites where we had data on natural and anthropogenic processes (soil occupancy), we compared the variations of these elements with the evolutionary trends of the coastline to try to detect possible correlations.

Comparing the results of the interpretation of the aerial images used (1981, 1996, and 2017) provided information that allowed us to understand the evolutionary behavior of the open sea line over 37 years. Variations in the position of the full sea line between 1981 and 2017 show a general progressive evolutionary trend along the $5 \mathrm{~km}$ of coastline studied.

\section{Coastal Line Mobility (EPR)}

The study area was divided into 3 sectors from East to West (Table 4):

\section{Area A: Ghandouri beach:}

This sector to the East of the studied coast spreads over a length of about 1.2 $\mathrm{km}$, An erosion affected this part of Tangier Bay compared to its location in 1981. The average retreat rate is $-2.25 \mathrm{~m} /$ year, with a maximum of $+0.48 \mathrm{~m} /$ year and a minimum of $-1.26 \mathrm{~m} /$ year. Although there have been significant variations in the spatial and temporal evolution of the full sea line, these results may be slightly influenced by the margin of error $(+/-0.29 \mathrm{~m} /$ year), especially in areas of low agitation. An estimate of the area gained or lost was also made by superimposing and intersecting reference lines at the same level. Then, they were merged to form a single theme with ArcToolsbox and then converted into polygons in ArcCatalog and their surfaces are calculated automatically. The "GHANDOURI" beach sector presents a negative surface area balance which shows a decline of $1.912078 \mathrm{Ha}$ between 1981 and 2017 along the 48 transects studied (Figure 6).

\section{Sector B: The beach of Malabata:}

With a length of about $1.35 \mathrm{~km}$, this fringe shows an accretion of the coastline: The line has been advanced compared to its position in 1981, it has experienced 


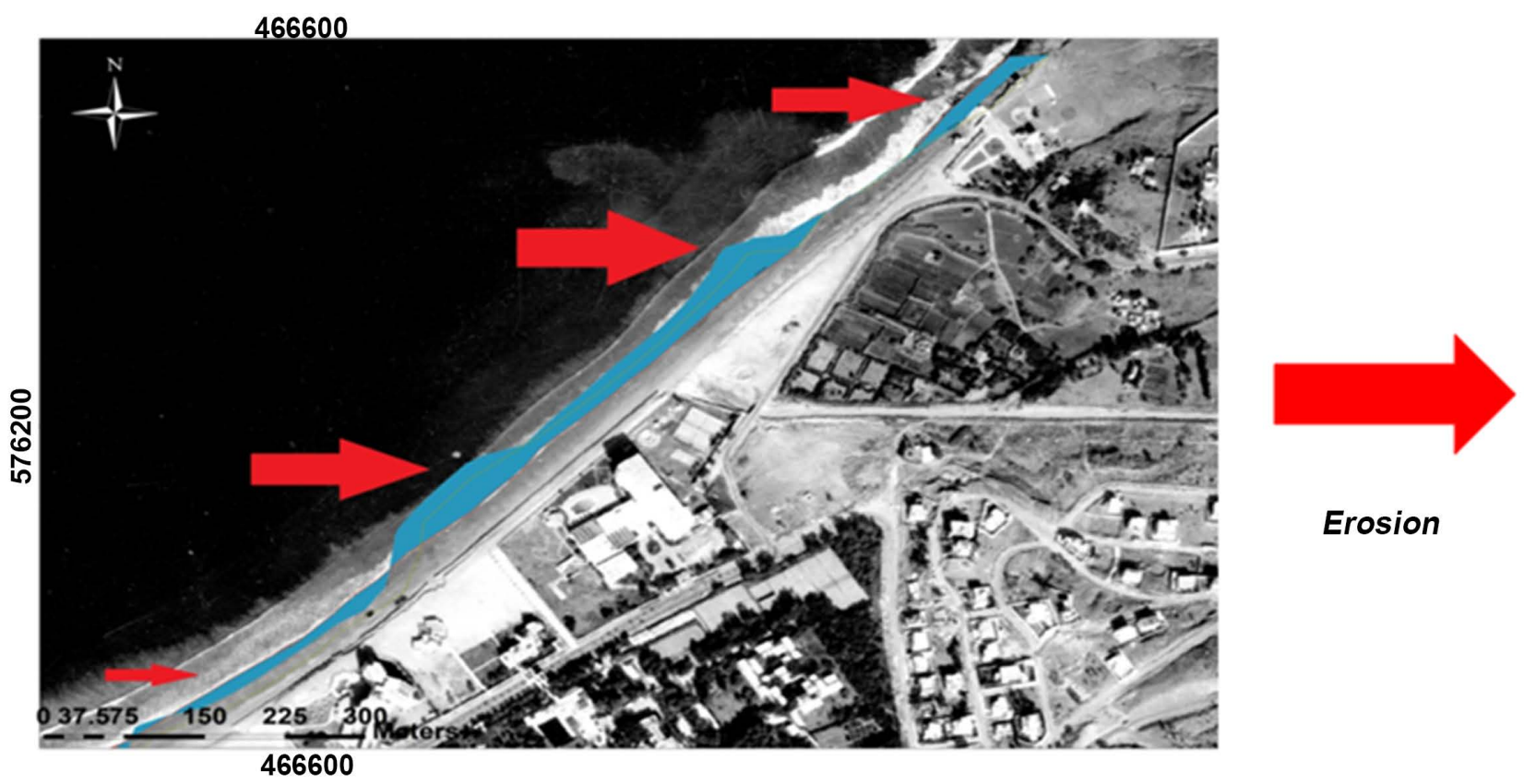

Figure 6. The evolution of the coastline at the Ghandouri beach from 1981 to 2017 calculated by the End Point Rate (EPR) method.

an average accretion rate of $+1.78 \mathrm{~m} /$ year (with a maximum of $+2.21 \mathrm{~m} /$ year and a minimum of $+0.86 \mathrm{~m}$ /year). As for the surface balance of Malabata beach, it is positive and shows an increase in surface area of 8.427789 Ha between 1981 and 2017 along the 54 transects studied (Figure 7).

Area $C$ : The municipal beach, this area in the west of the studied coast extends for a length of about $2 \mathrm{~km}$. It presents an accretion of the coastline on the port side with erosion to the west of the beach: the line was generally eroded compared to its 1981 situation, and has an average erosion rate of $-0.56 \mathrm{~m} /$ year (with a maximum of $+0.78 \mathrm{~m} /$ year and a minimum of $-3.24 \mathrm{~m} /$ year) (Figure 8 ).

The surface assessment Figure 9:

Ghandori Beach: 1.912078 Hectares;

Malabata Beach: 8.427789 Hectares;

Municipal Beach: 5.222961 Hectares.

Table 5 summarizes the change in the change rate of the coastline by periods.

- 1981 to 1996: The two beaches of Ghandouri and Malabata have been eroded with averages of $-12.48 \mathrm{~m}$ and $-49.28 \mathrm{~m}$ respectively, while the municipal beach has been accreted with an average of $26.4 \mathrm{~m}$ of period.

- 1996 to 2017: Evolutionary trends are predicted for the 3 beaches with period averages of $9.46 \mathrm{~m}$ for Ghandouri beach; $35.65 \mathrm{~m}$ and $1.44 \mathrm{~m}$ for the municipal beach.

\section{Discussion}

The use of aerial photographs has enabled us to trace the evolution of the coastline of Tangier Bay over the long term during the 1981-2017 period. The use 

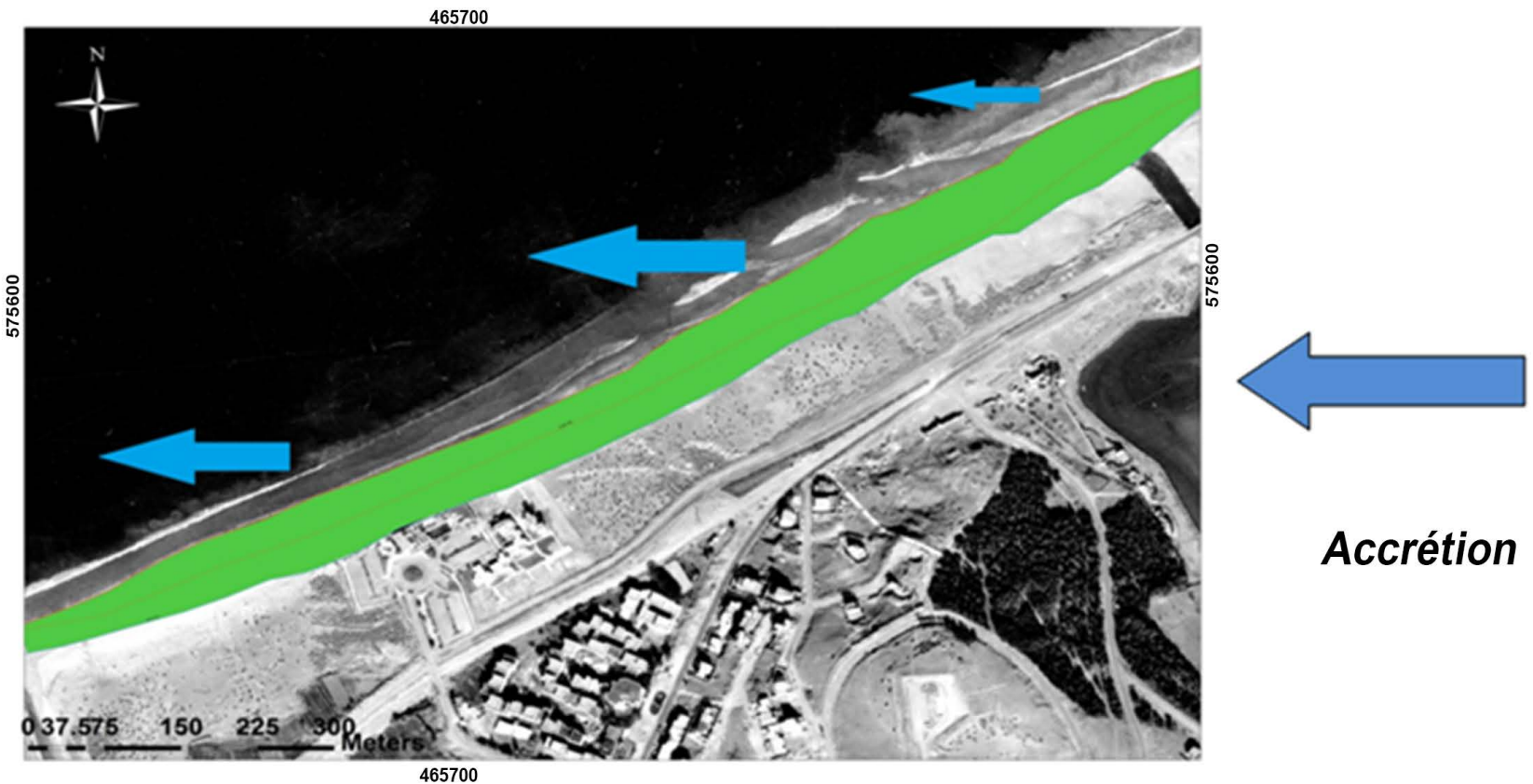

\section{Accrétion}

Figure 7. The evolution of the coastline at Malabata Beach from 1981 to 2017 calculated by the End Point Rate (EPR) method.

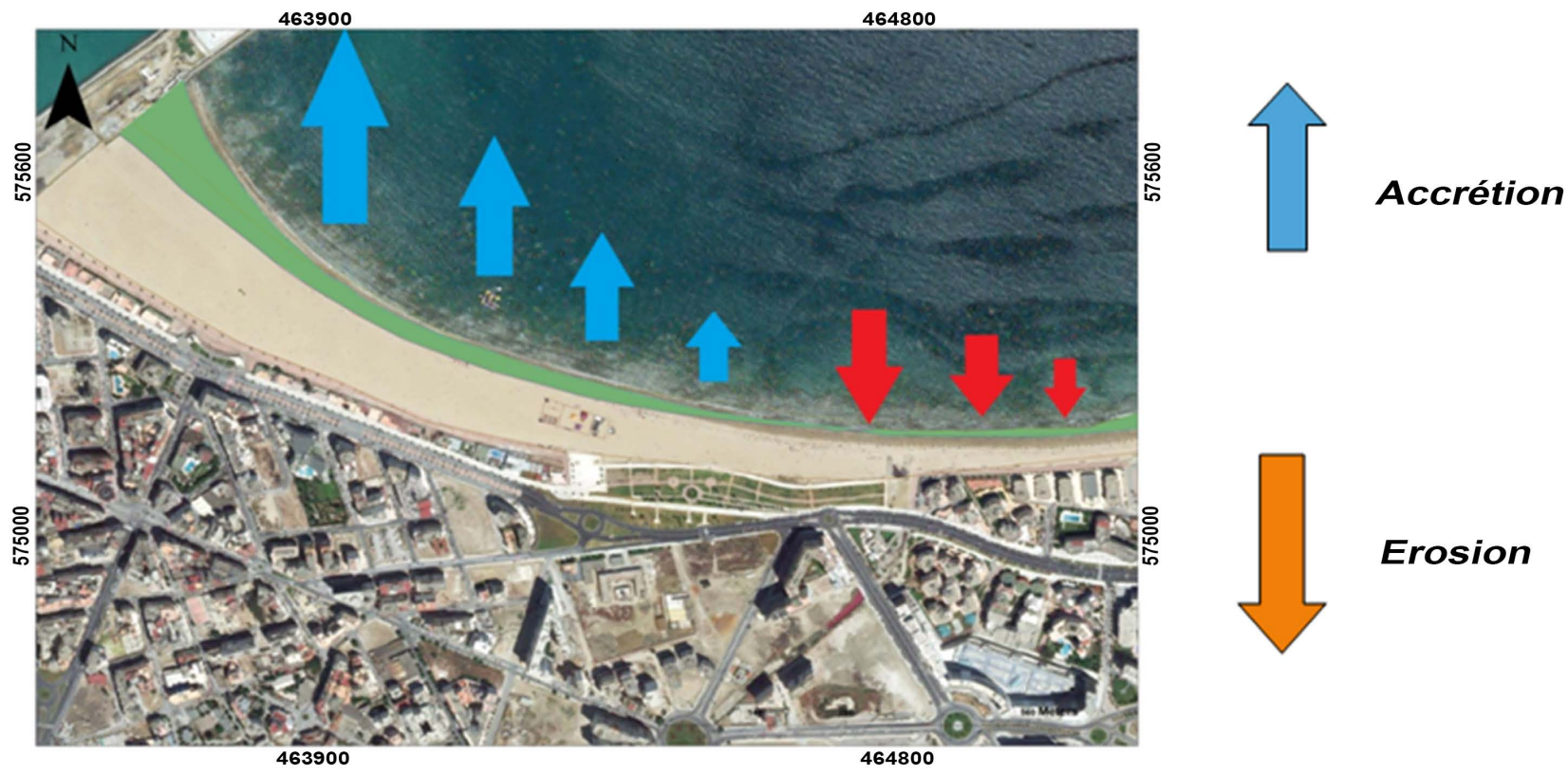

Figure 8. The evolution of the coastline at the municipal beach from 1981 to 2017 calculated by the End Point Rate (EPR) method.

of photo-interpretation for the diachronic study of the kinematics of the Tangier Bay coastline is essentially hampered by the quality of the available photographic data and the choice of a reference line that can be located on the multi-date plates. We determined the evolution of the solid sea line using the DSAS tool based on historical coastline features.

Based on the numerical analysis of the 1981-1996 and 2017 coastline lines on the coastal sector of Tangier Bay, it can be seen that Malabata beach is 


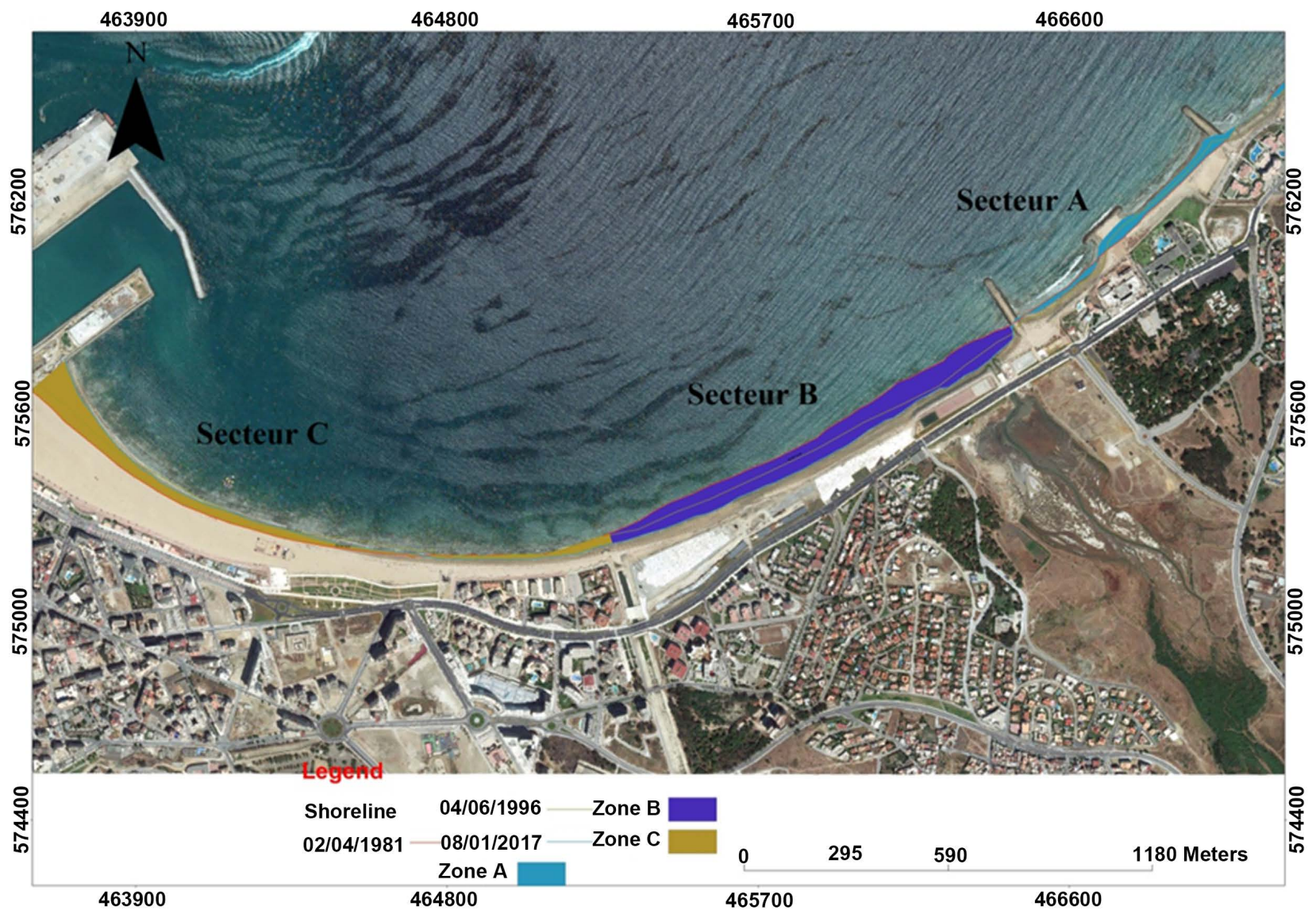

Figure 9. The surface area balance of the different sectors of Tangier Bay.

Table 4. The different statistics given by the EPR.

\begin{tabular}{|c|c|c|c|c|c|}
\hline & Study Areas & $\begin{array}{l}\text { Ghandori } \\
\text { Beach }\end{array}$ & $\begin{array}{l}\text { Malabata } \\
\text { Beach }\end{array}$ & $\begin{array}{l}\text { Municipal } \\
\text { Beach }\end{array}$ & $\begin{array}{c}\text { Coastal of the } \\
\text { Tangier Bay (total) }\end{array}$ \\
\hline & Number of transects & 48 & 54 & 76 & 178 \\
\hline & Length & 1.2 & 1.35 & 2 & 4,55 \\
\hline \multirow{3}{*}{ EPR } & Average coastal mobility (m/year) & -2.25 & +1.78 & $-0,56$ & 0.24 \\
\hline & Minimum of coastal mobility & -1.26 & $+0,86$ & -3.24 & -3.24 \\
\hline & Maximum coastal mobility & +0.48 & +2.21 & +0.78 & 2.21 \\
\hline
\end{tabular}

Table 5. Evaluation of the evolution rate of the coastline studied from 1981 to 2017.

\begin{tabular}{ccccc}
\hline \multirow{2}{*}{ Years } & \multicolumn{2}{c}{$1981-1996$} & \multicolumn{2}{c}{$1996-2017$} \\
\cline { 2 - 5 } & Annual average m/an & Period Average (m) & Annual average (m/an) & Period Average (m) \\
\hline Ghandori Beach & -0.78 & 12.48 & 0.43 & 9.46 \\
Malabata Beach & -3.08 & 49.28 & -1.556 & 35.65 \\
Municipal Beach & 1.65 & 26,4 & -0.063 & 1.44 \\
\hline
\end{tabular}

experiencing a downward trend with an average accretion rate of $+1.78 \mathrm{~m} /$ year whereas the municipal beaches and Ghandouri are mainly affected by erosion 
with average erosion rates of $-0.56 \mathrm{~m} /$ year and $-2.25 \mathrm{~m} /$ year respectively.

These results could be linked to the dominance of natural causes such as swell. This is evidenced by the effect of the currents generated by NW swells and NE waves, which are responsible for the distribution of sediments in the bay and beach degradation in the eastern part of the bay, while also favoring the fattening of the western sector. The influence of swell energy decreases from east to west of the bay, which explains the presence of fine facies in the western sector, particularly in the breakwater area. Another natural cause would be the action of storms, which are frequent in Tangier.

The evolution of the change rate of the coastline by periods shows an erosionary trend during the 1981-1996 period, followed by a pre-flooding trend between 1996 and 2017. The cause would be the anthropic effect, very apparent especially in the last 15 years, especially with the protective structures (the presence of the breakwater implies zones of deposit behind it, inducing the fattening of the beach behind the structure and the formation of tombolos. The ear located to the west of the structure intercepts the sediments in transit from east to west and thus creates a zone of significant erosion in the west) and the major conversion works from the port of Tangier to a marina and marina.

From the point of view of the reliability of the calculated rates of change, the methods used do not always yield identical results [18], the best match is found in the extreme point method (EPR) since the points are closer to the diagonal. This method is more correct in rocky areas where the identification of the selected reference line is difficult. For this reason, the results of the LNR and WLR methods were neglected.

\section{Conclusions}

The geographical position of the Moroccan coastline is complex and vulnerable because it is under increasing pressure. Its coastline is therefore highly threatened by degradation and erosion. Its management has proven its limitations and has only accentuated the various problems.

This research focuses on the constructive and useful function of GIS through the Arcgis software and its DSAS extension, for the case study of Tangier Bay.

The use of photo-interpretation and aerial photography has enabled us to study the diachronic kinematics of the coastline. Its interpretation allows us to determine the main factors that cause erosion and shows the impact of the port's reconversion work on the modification of the morphology of the bay.

While the natural causes are always obvious, such as swell, wind, currents, tides, etc., human activity is increasingly influencing the profile of beaches. Several erosion factors directly related to man can be cited:

- The over-frequenting of certain beaches, which deteriorates the dune massifs.

- The construction of harbors (e.g. the new Tangier Marina) prevents sediment from moving along the coast.

- The urbanization of the coastline, which reflects the swell and prevents waves from breaking out. Their energy is no longer dissipated along the beaches 
and the erosion phenomenon is increasing.

- The poor design of defensive works, which by fighting locally on a problem, displace it on the neighboring beaches.

- The construction of dams reduces the solid inputs from rivers flowing into the sea.

- The deterioration of marine plants that slow down coastal erosion by stabilizing the seabed and dissipating the energy of the swell, through pollution, trawls, wild anchorages ...

In a national and international context of environmental awareness, Morocco must find the conditions for a more "sustainable" development and an integrated approach, able to coordinate the multiple and interdependent interests of all sectors, while respecting environmental values.

\section{References}

[1] Hilal, A. (2016) L'espace littoral marocain entre pressions du présent et exigences de l'avenir: Cas du littoral d'Essaouira (Maroc). Cinq Continents, 6, 79-100.

[2] Achab, M., El Moumni, B., El Arrim, A. and Gutierrez Mas, J.M. (2005) Répartition des faciès sédimentaires récents en milieu marin côtier: Exemple des baies de Tanger (NW-Maroc) et de Cadix (SW-Espagne). 1-9.

[3] El Gharbaoui, A. (1981) La terre et l'homme dans la péninsule Tingitaine, étude sur l'homme et le milieu naturel dans la Rif occidental. Travaux de L'Institut Scientifique. Serie Geologie et Geographie Physique, No. 15, 439.

[4] Humbert, M. (1971) Carte géotechnique de Tanger: Géologie et géomorphologie. Notes Service géologique du Maroc, No. 222, 31-43.

[5] L.C.H.F. (Laboratoire Central Hydraulique de France) (1972) Baie de Tanger. Rapport de l'étude théorique sur document. 51.

[6] Long, B.F., Bencheikh, L., Karakiewicz, B., Merzouk, A. and et Romanczyk, W. (1999) Réhabilitation de la plage de Tanger par rechargement du haut de plage entre Ghandouri et le port. Direction des ports et du domaine public maritime, Rabat (Maroc), $19 \mathrm{p}$.

[7] Nombella, et al. (1987) Gao \& Collins 1994, et Olabarria et al. 1996.

[8] El Arrim, A., Maâtouk, M., El Hatimi, I., Afailal-Tribak, A. and El Moumni, B. (2002) Les sédiments superficiels de la baie de Tanger (Maroc): Nature et origine. Afr. Geosci. Rev., 9, 245-253.

[9] El Arrim, A., Maatouk, M., El Moumni, B., Afailal-Tribak, A. and El Khachani, H. (2003) Le littoral de la baie de Tanger (Rif Nord Occidental-Maroc): Sédimentologie, géochimie et impact de la dynamique sédimentaire. Trav. Inst. Sci. Rabat, sér. Géol. \& Géogr. Phys., 21, 215-223.

[10] El Abdellaoui, J. et André Ozer, (2007) Etude diachronique et historique de l'évolution du trait de côte de la baie de Tanger. 8-10.

[11] Shoshany, M. and Degani, A. (1992) Shoreline Detection by Digital Image Processing of Aerial Photography. Journal of Coastal Research, 8, 29-34.

[12] Appeaningaddo, K., Walkden, M. and Mills, J.P. (2008) Detection, Measurement and Prediction of Shoreline Recession in Accra, Ghana. ISPRS Journal of Photogrammetry and Remote Sensing, 63, 543-558. https://doi.org/10.1016/j.isprsjprs.2008.04.001

[13] Faye, I.B.N.D., Henaff, A., Gourmelon, F. and Diaw, A.T. (2008) Evolution du trait 
de côte à Nouakchott (Mauritanie) de 1954 à 2001 par photo-interprétation. Norois, $\mathrm{n}^{\circ} 208,2008 / 3,11-27$.

[14] Moore, L.J. (2000) Shoreline Mapping Technics. Journal of Coastal Research, 16, 111-124.

[15] Boak, E.H. and Turner, I.L. (2005) Shorelinedefinition and Detection: A Review. Journal of Coastal Research, 21, 688-703. https://doi.org/10.2112/03-0071.1

[16] Moore, L.J., Ruggiero, P. and List, J.H. (2006) Comparing Mean High Water and High Water Line Shorelines: Should Proxy-Datum Offsets Be Incorporated into Shoreline Change Analysis? Journal of Coastal Research, 22, 894-905.

[17] Crowell, M., Leatherman, S. and Buckley, M.K. (1991) Historical Shoreline Change: Error Analysis and Mapping Accuracy. Journal of Coastal Research, 7, 839-852.

[18] Stafford, D.B. and Langfelder, J. (1971) Air Photo Survey of Coastal Erosion. Photogrammetry Engineering, 37, 565-575.

[19] Dolan, R., Hayde, B.P., May, P. and May, S. (1980) The Reliability of Shoreline Change Measurements from Aerial Photographs. Shore Beach, 48, 22-29.

[20] Anders, F.J. and Byrnes, M.R. (1991) Accuracy of Shoreline Change Rates as Determined from Map and Aerial Photographs. Shore and Beach, 59, 17-26.

[21] Thieler, E.R. and Danforth, W. (1994) Historical Shoreline Mapping (I): Improving Techniques and Reducing Positioning Errors. Journal of Coastal Research, 10, 549-563.

[22] Provenchier et Dubois (2007) Précis de télédétection Tome 4 Méthodes de photointerprétation.

[23] Durand, P. (2000) Approche méthodologique pour l'analyse de l'évolution des littoraux sableux par photointerprétation. Photo-Interprétation, 2000, 3-18.

[24] Thieler, E.R., himmelstoss, E.A., Zichichi, J.L. and Ergul, A. (2009) The Digital Shoreline Analysis System (DSAS) Version 4.0-An ArcGIS Extension for Calculating Shoreline Change. Open-File Report, US Geological Survey Report No. 2008-1278. http://woodshole.er.usgs.gov/projectpages/dsas/version4/

[25] Thieler, E.R., Himmelston, E.A., Zichichi, J.R. and Miller, T.L. (2005) Digital Shoreline Analysis System (DSAS) Version 3.0: An ArcGis Extension for Calculating Shoreline Change. US Gelogical Survey Open File Report 2005-1304. 